\title{
Apresentação atípica envolvendo o trato gastrointestinal da doença do novo coronavírus (COVID-19): relato de caso
}

Atypical presentation involving the gastrointestinal tract of the new coronavirus disease (COVID-

19): case report

Presentación atípica que involucra el tracto gastrointestinal de la enfermedad del nuevo coronavirus (COVID-19): reporte de caso

Danielle Laís Lopes Barboza

ORCID: https://orcid.org/0000-0002-6237-2163 Universidade Federal do Delta do Parnaíba, Brasil E-mail: daniellelaislopes@gmail.com

Alba Angélica Nunes Mouta

ORCID: https://orcid.org/0000-0002-4093-0224 Universidade Federal do Delta do Parnaíba, Brasil E-mail: angelicanmouta@gmail.com

Ramodnil de Moura Santos

ORCID: https://orcid.org/0000-0002-4751-002X Centro Integrado de Especialidades Médicas, Brasil

E-mail: ramodnilmoura@ hotmail.com

Maria Rafaela Lobato Alves

ORCID: https://orcid.org/0000-0001-6564-7567 Universidade Federal do Delta do Parnaíba, Brasil

E-mail: rafaela_lahp@hotmail.com

Igor dos Santos Cavalcante ORCID: https://orcid.org/0000-0003-2907-9026

Universidade Federal do Delta do Parnaíba, Brasil E-mail: igorsc@live.com

Bianca de Amorim Cavalcanti de Oliveira ORCID: https://orcid.org/0000-0001-7389-3901 Faculdade de Medicina Nova Esperança, Brasil E-mail: bianca.cavalcanti@gmail.com

Lívia Nazaré Soares Silva Fernandes ORCID: https://orcid.org/0000-0001-9046-210X Faculdade de Medicina Nova Esperança, Brasil E-mail: liviaa.jua@gmail.com

Luiz Sabino Alves Junior

ORCID: https://orcid.org/0000-0003-3936-9983

Universidade Federal do Delta do Parnaíba, Brasil E-mail: luizsabinjr@gmail.com

\section{Resumo}

A doença do novo coronavírus (COVID-19) é caracterizada por uma ampla gama de sintomas e de apresentações clínicas. Os sintomas mais frequentes são febre, cefaléia, tosse seca, anosmia, ageusia; também pode afetar o trato gastrointestinal, sendo os principais sintomas relacionados a esse sistema: diarréia, dor abdominal, náusea e vômito. Os sintomas gastrointestinais são causados pela exacerbação do sistema imune, e não por lesão direta do vírus no tecido. Trata-se de um estudo descritivo, observacional, retrospectivo em forma de relato de caso que busca apresentar uma manifestação atípica de COVID-19 em uma paciente jovem do gênero feminino, residente do município de Parnaíba-PI. As informações e condutas adotadas no presente relato de caso apresentado foram extraídas dos dados provenientes do prontuário da paciente e das demais documentações de exames complementares, tanto os laboratoriais como os exames de imagem. Tendo em consideração a grande quantidade de sintomas ainda desconhecidos e que são oriundos da COVID-19, o conhecimento das bases patológicas da doença são de grande importância para conseguir conduzir melhor o atendimento e garantir um tratamento mais rápido, principalmente diante de casos mais graves.

Palavras-chave: Infecções por coronavírus; Sinais e sintomas; Gastroenterologia. 


\begin{abstract}
The new coronavirus disease (COVID-19) is characterized by a wide range of symptoms and clinical presentations. The most frequent symptoms are fever, headache, dry cough, anosmia, ageusia; it can also affect the gastrointestinal tract, the main symptoms being related to this system: diarrhea, abdominal pain, nausea and vomiting. Gastrointestinal symptoms are caused by an exacerbation of the immune system, not by direct injury of the virus to tissue. This is a descriptive, observational, retrospective study in the form of a case report that seeks to present an atypical manifestation of COVID-19 in a young female patient, resident of the city of Parnaíba-PI. The information and conduct adopted in the present case report were extracted from data from the patient's medical record and from other documentation of complementary tests, both laboratory and imaging tests. Considering the large number of symptoms that are still unknown and that come from COVID-19, knowledge of the pathological bases of the disease is of great importance to be able to better conduct care and ensure faster treatment, especially in the face of more severe cases.
\end{abstract}

Keywords: Coronavirus infections; Signs and symptoms; Gastroenterology.

\title{
Resumen
}

La nueva enfermedad por coronavirus (COVID-19) se caracteriza por una amplia gama de síntomas y presentaciones clínicas. Los síntomas más frecuentes son fiebre, dolor de cabeza, tos seca, anosmia, ageusia; también puede afectar al tracto gastrointestinal, estando los principales síntomas relacionados con este sistema: diarrea, dolor abdominal, náuseas y vómitos. Los síntomas gastrointestinales son causados por una exacerbación del sistema inmunológico, no por una lesión directa del virus al tejido. Se trata de un estudio descriptivo, observacional, retrospectivo en forma de reporte de caso que busca presentar una manifestación atípica de COVID-19 en una paciente joven, residente de la ciudad de Parnaíba-PI. La información y conducta adoptada en el presente caso clínico se extrajo de datos de la historia clínica del paciente y de otra documentación de pruebas complementarias, tanto de laboratorio como de imagen. Considerando la gran cantidad de síntomas que aún se desconocen y que provienen del COVID-19, el conocimiento de las bases patológicas de la enfermedad es de gran importancia para poder realizar mejor la atención y asegurar un tratamiento más rápido, especialmente ante casos más severos.

Palabras clave: Infecciones por coronavirus; Señales y síntomas; Gastroenterología.

\section{Introdução}

A doença do novo coronavírus (COVID-19) é caracterizada por uma ampla gama de sintomas e de apresentações clínicas. $81 \%$ dos pacientes apresentam formas leves, $14 \%$ podem evoluir para a forma grave e 5\% para a forma crítica, quando evoluem com Síndrome do Desconforto Respiratório Agudo (SDRA), sendo necessário suporte de oxigênio através da ventilação mecânica e leito em unidade de terapia intensiva (UTI) (Li et al., 2020)

Os sintomas mais frequentes são febre, cefaléia, tosse seca, anosmia, ageusia; também pode afetar o trato gastrointestinal, sendo os principais sintomas relacionados a esse sistema: diarréia, dor abdominal, náusea e vômito. Os sintomas gastrointestinais acometem entre 3 e 79\% dos pacientes com COVID-19, sendo mais comum nos casos graves. Em $22 \%$ dos pacientes, a diarreia pode ser o primeiro sintoma. Os sintomas gastrointestinais são causados pela exacerbação do sistema imune, e não por lesão direta do vírus no tecido (Almeida \& Chehter, 2020; Oba et al., 2020)

O coronavírus da Síndrome Respiratória Aguda 2 (SARS-CoV2) já foi identificado no epitélio do trato gastrointestinal de pacientes infectados, bem como foi isolado RNA viral nas fezes de pacientes acometidos pela COVID-19 (Almeida \& Chehter, 2020; Daawood, 2020).

No dia de elaboração deste estudo, 07 de fevereiro de 2021, existiam aproximadamente 106.000.000 pessoas infectadas em todo o mundo, com mais de 2.300.000 mortes devido complicações da doença. Em todo o mundo, 192 países já apresentaram casos registrados da doença. O Brasil é o terceiro país com mais casos registrados e ocupa a segunda posição no número de óbitos (Hopkins, 2020).

$\mathrm{Na}$ maioria dos pacientes, a doença se manifesta como uma síndrome gripal, que pode evoluir rapidamente para pneumonia e SDRA. Em pacientes idosos e imunossuprimidos é comum ocorrer uma evolução atípica da doença e/ou um agravamento rápido do quadro do paciente (Iser et al., 2020)

O objetivo deste estudo é relatar uma apresentação gastrointestinal atípica da COVID-19 em paciente adulta do gênero feminino. 


\section{Metodologia}

Trata-se de um estudo descritivo, observacional, retrospectivo em forma de relato de caso que busca apresentar uma manifestação atípica de COVID-19 em uma paciente jovem do gênero feminino, residente do município de Parnaíba-PI, acompanhada pelo Centro de Especialidades Médicas (CIEM) e fomentada pela FAPEPI a correlacionar os sintomas apresentados com estudos publicados na literatura. As informações e condutas adotadas no presente relato de caso apresentado foram extraídas dos dados provenientes do prontuário da paciente e das demais documentações de exames complementares, tanto os laboratoriais como os exames de imagem. Com relação aos aspectos éticos do presente trabalho, foram fornecidas informações à paciente por meio do Termo de Consentimento Livre e Esclarecido (TCLE) e a autorização da realização do estudo ocorreu mediante assinatura deste documento. Os materiais utilizados para a revisão bibliográfica foram obtidos através de artigos publicados em bases de dados como Scielo, Pubmed e Lilacs.

\section{Relato de Caso}

Paciente do gênero feminino, 34 anos, compareceu ao serviço de atendimento médico Hospital Estadual Dirceu Arcoverde, na cidade de Parnaíba-Piauí, apresentando dor abdominal intensa no quadrante inferior direito de caráter progressivo há 7 dias, acompanhado de diarreia, náuseas e vômito. Paciente nega episódios semelhantes anteriores, nega perda de peso ponderal considerada, nega presença de muco nas fezes e histórico de diarreia crônica. Na admissão no Pronto Socorro, a paciente realizou uma tomografia computadorizada (TC) de região abdominal, uma ultrassonografia (USG) de abdome total e uma vídeo-íleo-colonoscopia, disponível na figura 1, nas quais constatou-se um espessamento parietal de cólon ascendente, associado a densificação mesentérica e proeminência numérica de linfonodos adjacentes sugestivos de processos inflamatório/infeccioso, não podendo ser descartado lesão de outra etiologia. Na USG, visualizou-se um espessamento parietal difuso de alça colônica em hipocôndrio e flanco direito, associado a leve densificação de gordura adjacente com discreta quantidade de líquido livre, sugerindo condição inflamatória. No vídeo-ileocolonoscopia, foi constatado a presença de uma hiperemia discreta e friabilidade de tecido, tendo como hipótese o diagnóstico de uma colite em área de cólon ascendente, a paciente permaneceu internada na enfermaria da unidade hospitalar pois apresentava risco de sepse diante dos sintomas apresentados. Devido aos sintomas apresentados e ao período envolvendo o surto de SARS-CoV 2, foi solicitado que a paciente fosse testada para comprovar ou afastar a possibilidade de os sintomas manifestados advirem de uma possível contaminação por COVID, o teste foi reagente para SARS-CoV2, o método utilizado para a comprovação foi a imunocromatografia para rastreio de anticorpos. Após comprovar que os sintomas apresentados pela paciente eram provocados pela COVID, todas as condutas voltaram-se a tratar essa patologia e a paciente passou a evoluir positivamente ao tratamento empregado, até chegar a data de sua alta hospitalar. 
Figura 1 - Imagem da vídeo-íleo-colonoscospia mostrando discretas alterações em cólon ascendente.
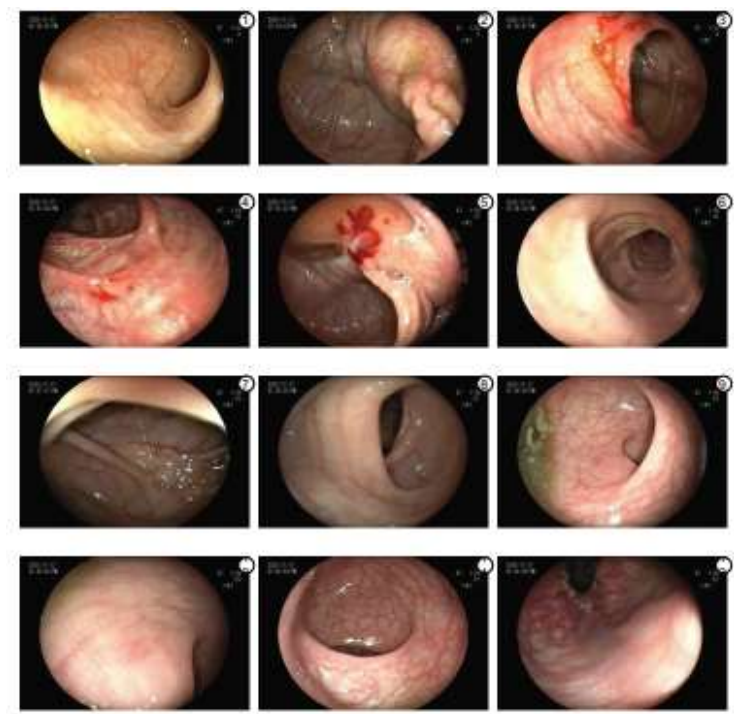

Fonte: Autores (2020)

\section{Discussão}

O SARS-CoV 2 utiliza a enzima conversora de angiotensina 2 (ECA2) como receptor para adentrar as células, os locais onde existem essa enzima são no trato respiratório, no tecido cardíaco e no trato gastrointestinal, neste último estando presente na borda em escova da mucosa intestinal. A ECA2 da mucosa intestinal está ligada à regulação da flora intestinal e no transporte de aminoácidos, o que explica a ocorrência dos sintomas, como a diarreia (Almeida \& Chehter, 2020).

A ECA2 é expressa em grande quantidade nas células alveolares tipo 2. O vírus pode ativar a ECA2 e levar a ativação do sistema renina-angiotensina e aumentar a permeabilidade vascular, o que pode causar a lesão pulmonar. Algumas condições como: hipertensão, diabetes, doenças cardiovasculares, tabagismo e doença pulmonar obstrutiva crônica (DPOC) podem aumentar a quantidade de ECA2, portanto, esses pacientes podem ser mais suscetíveis a desenvolverem formas graves da COVID-19. Assim como pacientes em uso de medicações dos grupos de inibidores da enzima conversora de angiotensina (IECA) e bloqueadores de receptores de angiotensina (BRA) também são mais suscetíveis às formas graves. (Costa et al., 2020; Yang, et al., 2020). A paciente do nosso estudo não apresentava qualquer condição que a colocasse no grupo de risco para desenvolver formas atípicas ou graves da COVID-19.

Os sintomas gastrointestinais não estão relacionados diretamente com lesão do epitélio, mas sim devido uma exacerbação do sistema imune, os pacientes com COVID-19 podem desenvolver a chamada tempestade de citocinas, que podem ser originadas ou agravadas pelo trato gastrointestinal, visto que o intestino possui muito tecido linfóide em sua extensão. Durante esse processo, ocorre uma exacerbação na produção de citocinas, levando a um grande problema inflamatório, quanto maior a replicação viral, maior a atividade inflamatória (Almeida \& Chehter, 2020; Esper et al., 2020).

O quadro predominante da COVID-19, são os sintomas gripais, no entanto, uma parcela dos infectados podem iniciar o quadro apenas com sintomas gastrointestinais, também existem os pacientes que apresentam somente esses sintomas (Iser et al., 2020). A não ocorrência de sintomas respiratórios pode levar a um atraso no diagnóstico desses pacientes e consequentemente uma maior chance de contaminação de outras pessoas, bem como, pode levar a um agravamento do quadro do paciente devido a ausência de um diagnóstico, podendo evoluir para quadro de sepse de foco abdominal (Amaral et al., 2020). 
Em estudo conduzido por Amaral et al., 2020, foram acompanhados 10 pacientes com COVID-19 que iniciaram o quadro com sintomas gastrointestinais, sendo todos submetidos a tomografia computadorizada de abdome, 2 apresentaram alterações nesse exame de imagem, sugerindo o acometimento do sistema digestivo pelo SARS-CoV2. A dor abdominal e a diarreia estavam presentes em $80 \%$ desses pacientes. Uma das pacientes apresentou imagens sugestivas de divertículos no cólon sigmóide, com paredes espessadas e estriações da gordura adjacente. A segunda paciente, apresentou espessamento do cólon ascendente e do íleo distal, associado a estriações da gordura subjacente, sendo sugestivo de enterocolite (Amaral et al., 2020).

Alguns exames laboratoriais podem estar ligados relacionadas a sintomas gastrointestinais e indicar um mau prognóstico para o caso, dentre os exames a serem realizados, são citados: aumento da AST, ALT e bilirrubina, aumento de ddímero e protrombina, proteína C-reativa, procalcitonina, ferritina e triglicerídeos; além da redução de leucócitos, linfócitos e sódio (Almeida \& Chehter, 2020; Oba et al., 2020).

\section{Conclusão}

No Brasil, os registros de apresentações atípicas envolvendo o SARS-CoV 2 necessitam de mais estudos, principalmente, quando há evolução mais grave do caso manifestado. Fomentar a produção intelectual na área, auxiliará outros profissionais de saúde a conseguirem identificar melhor as diferentes sintomatologias que um paciente possa apresentar durante o atendimento e é de fundamental importância para o manejo adequado das situações abordadas independente de se está realizando o atendimento. Tendo em consideração a grande quantidade de sintomas ainda desconhecidos e que são oriundos da COVID-19, o conhecimento das bases patológicas das doenças é de grande importância para conseguir conduzir melhor o atendimento e garantir um tratamento mais rápido, principalmente diante de casos mais graves.

\section{Referências}

Almeida, J. F. M., \& Chehter, E. Z. (2020) COVID-19 e o trato gastrintestinal: o que já sabemos? Einstein. 18(3).

Amaral, L. T. W., Brito, V. M., Beraldo, G. L., Fonseca, E. K. U. N., Yokoo, P., Talans, A., Oranges Filho, M., Chate, R. C., Baroni, R. H., \& Szarf, G. (2020). Sintomas abdominais como manifestação inicial da COVID-19: uma série de casos. Einsten. 18.

Costa, I. B. S. S., et al. (2020). O Coração e a COVID-19: O que o Cardiologista Precisa Saber. Arq Bras Cardiol.

Dawood, A. A. (2020) Mutated COVID-19 may foretell a great risk for mankind in the future. New Microbe and New Infect. 35.

Esper, R. B., et al. (2020). Tratamento empírico com hidroxicloroquina e azitromicina para suspeita de casos de COVID-19 acompanhados por telemedicina.

Hopkins, J. (2020). Mapa do coronavirus. https://coronavirus.jhu.edu/map.html.

Iser, B. P. M., Silva, I., Raymundo, V. T., Poleto, M. B., Schuelter-Trevisol, F., \& Bobinski, F. (2020). Definição de caso suspeito da COVID-19: uma revisão narrativa dos sinais e sintomas mais frequentes entre os casos confirmados. Epidemiol. Serv. Saúde. 29(3).

Li, R., et al. (2020) Estimated Demand for US Hospital Inpatient and Intensive Care Unit Beds for Patients With COVID-19 Based on Comparisons With Wuhan and Guangzhou, China. JAMA Network Open. 3(5).

Oba, J., Carvalho, W. B., Silva, C. A., \& Delgado, A. F. (2020). Sintomas gastrintestinais e abordagem nutricional durante a pandemia de COVID-19: guia prático para pediatras. Einstein. 18:1-8.

Yang, C. L., et al. (2020). Coronavirus disease 2019: a clinical review. European Review for Medical and Pharmacological Sciences. 24. 